\title{
QUANTIFICATION OF HEAVY METALS IN CANNED TOMATO PASTE SOLD IN UBANI-UMUAHIA, NIGERIA
}

\author{
RI Uroko ${ }^{1}$, VE Okpashi2 ${ }^{*}$, NE Etim ${ }^{3}$ and AC Fidelia ${ }^{1}$ \\ ${ }_{1}^{1}$ Department of Biochemistry, Micheal Okpara University of Agriculture Umudike, Nigeria \\ 2Department of Biochemistry, Cross River University of Technology, Calabar, Nigeria \\ ${ }^{3}$ Department of Environmental Education, University of Calabar, Nigeria
}

\begin{abstract}
In recent years there has been an increase in the contaminations of heavy metals on the environment. Government and private organization have shown their interest in the effect of dietary exposure to several heavy metals. These heavy metals have been implicated in the etiology of many diseases with high risk to humans. Canned tomatoes paste is one of the important health deterioting factors to human health in Ubani-Umuahia, Nigeria. In this study atomic absorption spectrophotometer was used to screen for nine heavy metals concentration in ten different brands of canned tomatoes paste sold at Ubani-Umuahia market in Nigeria. Human risk assessment was calculated using the collated data to evaluate the predictive risk of human health after the consumption of canned tomatoes paste. Results shows that lead and nickel were not detected in all the canned tomatoes. In comparison low concentrations of copper, iron, and manganese were notated but high concentrations of chromium and cadmium were detected in all the tested tomatoes pastes. Cobalt and zinc concentration was notated lower than permissible limit. The daily intake of copper, cobalt, manganese, chromium, cadmium, nickel, iron, zinc and lead were below their tolerable values in canned tomatoes. The predicted lifetime for carcinogens to occur was less than one $(<1)$. Copper, cobalt, iron, and zinc were below the acceptable value for non-cancer risk with $\mathrm{HQ}<1$. The risk of incurring cancer by ingesting canned tomatoes was within the lifetime predicted a range of $(1.0 \mathrm{E}-6$ to $1.0 \mathrm{E}-4)$. Finds suggest that prolong and persistent consumption of these heavy metals may cause toxicity and consequential heath challenges.
\end{abstract}

Key words: Canned tomatoes, Heavy metals, Human health, Food safety

\section{Introduction}

Heavy metals are non-biodegradable and hazardous contaminants in food and the environment. They have an extended biological half-life (Heidarieh et al. 2013). Public health and environmental quality have been a global issue of concern. Human exposure to environmental contaminants has risen due to an exponential increase in the industrial, agricultural, domestic and technological application (Bradl 2002). The source of heavy metals in the environment includes geogenic, industrial, agricultural, pharmaceutical, domestic effluents and atmospheric sources (He and Yang 2005). Although heavy metals are naturally occurring elements that are found in the earth crust, most environmental contamination are caused anthropogenic activities such as mining and smelting operations, industrial production and use of metals-compounds $\mathrm{He}$ and Stoffella (2005). The heavy metals include cadmium, chromium, copper, mercury, lead, and zinc. Some of these metals are micronutrients necessary for plant growth, such $\mathrm{Zn}, \mathrm{Cu}, \mathrm{Mn}, \mathrm{Ni}$, and $\mathrm{Co}$, while others have unknown biological functions such as $\mathrm{Cd}, \mathrm{Pb}$, and $\mathrm{Hg}$ (Lasat 2006).

*Author for correspondence: Vic2reshu@gmail.com 
Metal corrosion, atmospheric deposition, soil-metal erosion, leaching of heavy metals, sedimentation and resuspension, and metal evaporation from water resources are major routes of transferring heavy metals to the water column. It has been reported that heavy metals such as cobalt $(\mathrm{Co})$, copper $(\mathrm{Cu})$, chromium $(\mathrm{Cr})$, iron $(\mathrm{Fe})$, magnesium $(\mathrm{Mg})$, manganese $(\mathrm{Mn})$, nickel $(\mathrm{Ni})$ and zinc $(\mathrm{Zn})$ are essential nutrients required for different biochemical and physiological functions (WHO/FAO/IAEA 1996). Therefore, a fall in the supply of these nutrients may result in deficiency, diseases or syndrome (WHO/FAO/IAEA 1996). Canned tomato paste is one of the most widely consumed products in the world. They are rich in minerals, vitamins, essential amino acid, sugars, and dietary fibers. Tomatoes contain vitamin B and C, iron and phosphorous (Stencheva et al. 2014). Canning is a preservative technique used to prevent seal products from spoilage by sustaining their shelf life. They are designed to inhibit spoilage bacteria and changes that may undermine tomatoes quality. Heavy metals may be present in canned tomato paste through uptake by plants from contaminated soil, polluted water and from applied agrochemicals. The harvested fruits may become contaminated during canning processes due to leaching from the metal containers into the canned product during storage (Nincevic et al. 2009, Nathaniel et al. 2012). Toxic heavy metals such as Pb, Co, and Cd can be differentiated from other pollutants since they are not biodegradable. They have the tendency to bioaccumulate in a living organism, thus causing various alterations as they compete for a binding site with normal metals (Song and Li 2014). Cadmium is a toxic industrial and environmental pollutants classified as a human carcinogen. Cadmium is known to be toxic at traced level and is well implicated as probable carcinogens. Severe exposure to cadmium has resulted in deregulation of the pulmonary compartments such as bronchiolitis, emphysema, and alveolitis (Kabata-Pandas 2011).

Cadmium toxicity may cause osteoporosis by inducing renal tubular dysfunction with a consequent increase in the loss of electrolytes such as calcium and phosphate with a direct effect on bone osteoblast and osteoclast activity (Kazantziz 2004). A higher concentration of cadmium is absorbed in the kidney, while an estimated $30 \mathrm{mg}$ of cadmium is commonly inhaled throughout human, childhood, and adolescences (Tchounwou et al. 2012). Zinc toxicity is a medical condition involving an overdose, or toxic upon exposure to zinc. Such toxicity level of zinc has occurred after the ingestion of about $225 \mathrm{mg}$ or over (Wheal et al. 2013). Excessive ingestion of zinc can suppress the absorption of copper and iron. The free zinc ion in solution is also toxic to bacteria, plant vertebrates, and fishes. Children are particularly susceptible to lead intoxication, at low blood concentrations of lead, various neurological and behavioral problems may occur, ranging from a rise in the hearing threshold to a reduction in intelligence quotient (Farooq et al. 2008). In the environment, lead is too toxic to plants, animals, and microorganisms. The effects of lead are linked to contaminated areas. Lead contamination in the environment exists in an insoluble form, and the toxic metals pose a serious human health problem, namely, brain damage and retardation (Chui et al. 2013). Therefore, this study quantifies the total concentration of nine heavy metals ( $\mathrm{Pb}, \mathrm{Ni}, \mathrm{Cu}, \mathrm{Co}, \mathrm{Cr}, \mathrm{Cd}, \mathrm{Fe}, \mathrm{Mn}$, and $\mathrm{Zn}$ ) in ten brands of canned tomato pastes sold in the Ubani-Umuahia market in Imo state, Nigeria. Predictive risk assessment of human health exposed to heavy metals was also evaluated. Other perceived risk analyzed include determinations of daily intake of metals, hazard quotients of heavy metals, hazard index, carcinogenic risk, and total cancer risk, respectively. 


\section{Materials and Methods}

\section{Materials}

Tomatoes: Ten different brands of canned tomatoes pastes were purchased from Ubani-Umuahia market in Imo state, Nigeria and were used for this study. They include Gino, Clappa, Spandish, Dishes, 5-star, Hanno, Stella berry, Happi, Mama Prince, and Sarah. The canned tomatoes pastes were designated alphabeticallyA, B, C, D, E, F, G, H, I and J, respectively.

Chemical reagents: All reagents were of analytical grade, standard stock solutions of cadmium, lead, zinc, manganese chromium, copper, cobalt, nickel and iron were prepared from titrasol $(1000 \mathrm{mg} / \mathrm{l})$ and diluted to the desired concentrations. The working solutions were freshly prepared by diluting with an appropriate aliquot of the stock solutions using $10 \%$ trioxocarbonate.

Preparation of samples: The canned tomatoes paste were removed from the tin and inserted into a foil and placed inside a micro wave oven at $70^{\circ} \mathrm{C}$ to dry. Thereafter, they were mortared into powder.

Digestion of samples: The canned tomatoes were digested for heavy metal analysis using a concentrated mixture of $\mathrm{HNO}_{3}, \mathrm{HCLO}_{4}$ and $\mathrm{HF}$ in a ratio of 5:1:1. For each canned tomatoes sample, $0.5 \mathrm{~g}$ of dried sample was digested with $\mathrm{HNO}_{3}$ and $\mathrm{HCLO}_{4}$ in a ratio of $5: 1$, until a transparent solution was obtained. The digested tomatoes paste were filtered and diluted with 50 and $25 \mathrm{ml}$ of distilled water. The heavy metals in the acid digest of the canned tomatoes were analyzed with atomic absorption spectrophotometer (AAS).

Determination of daily intake of heavy metals (dim): The daily intake of heavy metals (DIM) was determined according to the method prescribe by (Rattan et al. 2005) using the equation: DIM

$=\frac{C_{\text {matal }} D_{\text {food intaks }}}{B_{\text {averags wright }}}$

Where $C_{\text {metal }} D_{\text {food }}$ and $B_{\text {average }}$ represent the heavy metal concentrations in canned tomatoes paste $(\mathrm{mg} / \mathrm{kg})$ conversion factor, daily intake of canned tomatoes pastes (300 g/kg and $400 \mathrm{~g} / \mathrm{kg}$ ) outlined by (EPA 1989). The average body weight used in this study was $62 \mathrm{~kg}$, as a determining factor of averaging a body weight of 400 adults measured with a bathroom scale.

Determination of hazardous quotient (HQ): Hazardous Quotient (HQ) for the consumers inclined to the consumption of contaminated vegetables was assessed by the ratio of Daily Intake Rate (DIR) to the oral reference dose $\left(R_{f} D_{0}\right)$ for each metal USEPA (2013). If the value of $H Q$ is less than 1 , then the exposed local population (consumers) is said to be safe, but if $\mathrm{HQ}$ is equal to or greater than $1(\leq 1)$, it is considered unsafe for human health. Human health (HQ) caused by the consumption of vegetable was calculated by the following equation:

$$
\mathrm{HQ}=\frac{D I R}{R f D o}
$$

Where the oral reference dose $\left(R_{f} D_{0}\right)$ is an estimate of a daily oral exposure for the human population, which does not cause negative effects during a lifetime (EPA 1997). Oral reference dose of heavy metals in canned 
tomatoes paste was - Lead (0.0040), Nickel (0.02), Copper (0.040), Cobalt (0.043), Iron (0.070), Chromium (0.15), Cadmium (0.00010), Manganese (0.014) and Zinc (0.30), respectively EPA (1997).

Determination of hazardous index $(\mathrm{HI})$ : To estimate the risk to human health through more than one HM, the hazard index (HI) developed by (USEPA 1989) captured the hazard quotients for all HMs. Hazard index was calculated with the following equation (Guerra et al. 2010). $\mathrm{HI}=\Sigma \mathrm{HQ}=\mathrm{HQ}_{\mathrm{fe}}+\mathrm{HQ}_{\mathrm{Zn}}+\mathrm{HQ}_{\mathrm{Cr}}+\mathrm{HQ}_{\mathrm{Cu}}$ $+\mathrm{HQ}_{\mathrm{Mn}}+\mathrm{HQ}_{\mathrm{Co}}+\mathrm{HQ}_{\mathrm{Cd}}+\mathrm{HQ}_{\mathrm{Pb}}+\mathrm{HQ}_{\mathrm{Ni}}$

Carcinogenic risk index (CRI): The slope factor is an acceptable model used in estimating the probability of a response per unit intake of a chemical over a lifetime. The slope factor can be used to estimate the upper bound probability of an individual developing cancer as a result of lifetime exposure to a carcinogen (EPA 1989). The risks of cancer are expressed in the probability that one may develop cancer at a given lifetime due to exposure level. The cancer risk was calculated using equations 4 (Wu et al. 2016). Cancer risk = EDI $\times$ CSF.

Where EDI = daily intake of carcinogenic metals (mg/kg/day), which represent the lifetime average daily intake of carcinogens. The cancer risk is obtained using the cancer slope factor which is contaminant specific. The carcinogenic metals whose lifetime cancer risks were calculated with cancer slope factor (CSF) are $\mathrm{Cd}, \mathrm{Cr}, \mathrm{Pb}$ and $\mathrm{Ni}$ with $0.38,0.5,0.0085$, and 1.7 , respectively. Any cancer risk in the range of $10^{-6}$ and $10^{-4}$ is considered as been safe by the USEPA (1989).

Total cancer risk: The cumulative cancer risk due to exposure to multiple carcinogenic heavy metals via consumption of a particular type of canned tomatoes paste was assumed to be the sum of the individual heavy metal increment risk and was calculated by the following equations (Yang and Stofella 2005). Total cancer risk $=\sum E D I_{k} C S F_{k}$

Where EDI is the estimated daily intake of carcinogenic substance (mg/kg/day) and CSF is the slope factor of substance $(\mathrm{mg} / \mathrm{kg} / \mathrm{day})$

Statistical analysis: Descriptive statistics and one-way analysis of variance (ANOVA) were employed in the assessment of variation $(p<0.05)$ in metal concentration among canned tomatoes pastes of the same brand and across canned tomatoes of different brands.

\section{Results}

\section{Heavy metal concentration in canned tomatoes sold at Ubani market}

Table 1 showed that lead and nickel were not detected in all the canned tomatoes, but trace concentration of copper, iron and manganese were detected in all the canned tomatoes compared with respective permissible limit in canned tomatoes. However, significantly $(p<0.05)$ higher concentration of chromium and cadmium were detected in all the canned tomatoes relative to their respective permissible limit. Tomato $E$ and $J$ have both the highest and lowest chromium content while $\mathrm{F}$ and $\mathrm{J}$ had near concentrations $(0.055$ and 0.003$)$. Cadmium was the highest in tomato $\mathrm{D}$. Cobalt was detected in all the canned tomato exception of $\mathrm{J}$ where cobalt concentration significantly $(p<0.05)$ lowers than the permissible limit. 
Table 1. Concentrations of heavy metals in canned tomatoes sold at Ubani market in Umuahia

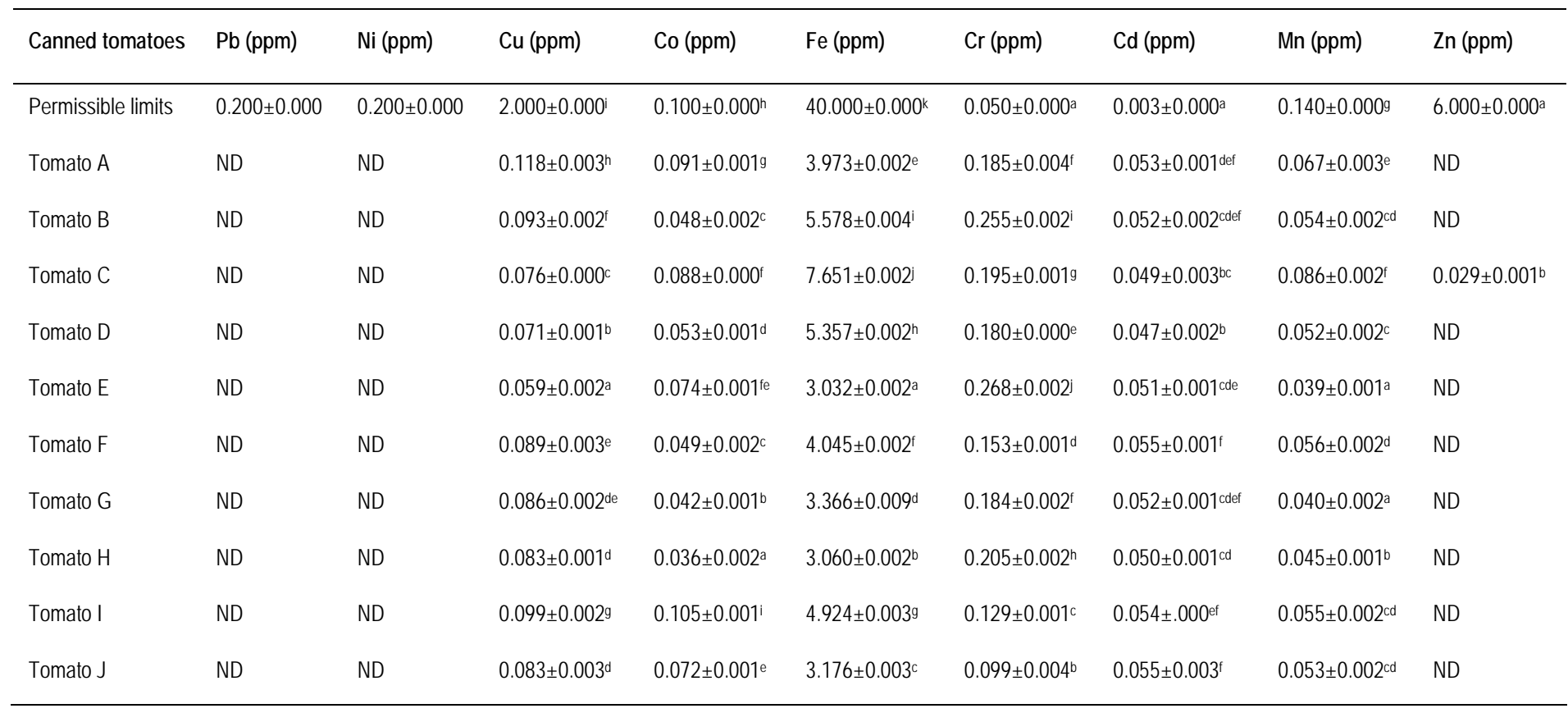

Values are presented as mean \pm standard deviation $(n=3)$, values with different letters $(a, b, c, d, e, f, g, h$ and i) as supper scripts in each of the columns are significantly $(\mathrm{p}<0.05)$ different. $\mathrm{ND}=$ Not Detected. 


\section{Daily intake of heavy metals in canned tomatoes paste sold at Ubani market}

The daily intake of heavy metals in canned tomatoes indicates no daily intake of lead and nickel in all the canned tomatoes. It was observed that the daily intake of copper, cobalt, iron, chromium, manganese and cadmium from all the canned tomatoes had values below the tolerable daily intake. Daily intake of zinc was observed in canned tomato $\mathrm{C}$ only and was below permissible limit see Table 2.

Table 2. Daily intake of heavy metals in canned tomatoes pastes sold in Umuahia market (mg/kg/day)

\begin{tabular}{llllllllll}
\hline $\begin{array}{l}\text { Canned } \\
\text { tomatoes }\end{array}$ & $\mathrm{Pb}$ & $\mathrm{Ni}$ & $\mathrm{Cu}$ & $\mathrm{Co}$ & $\mathrm{Fe}$ & $\mathrm{Cr}$ & $\mathrm{Cd}$ & $\mathrm{Mn}$ & $\mathrm{Zn}$ \\
\hline Tomato A & - & - & $5.7 \mathrm{E}-04$ & $4.4 \mathrm{E}-04$ & $1.9 \mathrm{E}-02$ & $9.0 \mathrm{E}-04$ & $2.6 \mathrm{E}-04$ & $3.2 \mathrm{E}-04$ & - \\
Tomato B & - & - & $4.5 \mathrm{E}-04$ & $2.3 \mathrm{E}-04$ & $2.7 \mathrm{E}-03$ & $1.2 \mathrm{E}-03$ & $2.5 \mathrm{E}-04$ & $2.6 \mathrm{E}-04$ & - \\
Tomato C & - & - & $3.7 \mathrm{E}-04$ & $4.3 \mathrm{E}-04$ & $3.7 \mathrm{E}-04$ & $9.4 \mathrm{E}-04$ & $2.4 \mathrm{E}-04$ & $4.2 \mathrm{E}-04$ & $1.4 \mathrm{E}-04$ \\
Tomato D & - & - & $3.4 \mathrm{E}-04$ & $2.6 \mathrm{E}-04$ & $2.6 \mathrm{E}-02$ & $8.7 \mathrm{E}-04$ & $2.3 \mathrm{E}-04$ & $2.5 \mathrm{E}-04$ & - \\
Tomato E & - & - & $2.9 \mathrm{E}-04$ & $3.6 \mathrm{E}-04$ & $1.5 \mathrm{E}-02$ & $1.3 \mathrm{E}-03$ & $2.5 \mathrm{E}-04$ & $1.9 \mathrm{E}-04$ & - \\
Tomato F & - & - & $4.3 \mathrm{E}-04$ & $2.4 \mathrm{E}-04$ & $2.0 \mathrm{E}-02$ & $7.4 \mathrm{E}-04$ & $2.7 \mathrm{E}-04$ & $2.7 \mathrm{E}-04$ & - \\
Tomato G & - & - & $4.2 \mathrm{E}-04$ & $2.0 \mathrm{E}-04$ & $1.6 \mathrm{E}-02$ & $8.9 \mathrm{E}-04$ & $2.5 \mathrm{E}-04$ & $1.9 \mathrm{E}-04$ & - \\
Tomato H & - & - & $4.0 \mathrm{E}-04$ & $1.7 \mathrm{E}-04$ & $1.5 \mathrm{E}-02$ & $9.9 \mathrm{E}-04$ & $2.4 \mathrm{E}-04$ & $2.2 \mathrm{E}-04$ & - \\
Tomato I & - & - & $4.8 \mathrm{E}-04$ & $5.1 \mathrm{E}-04$ & $2.4 \mathrm{E}-02$ & $6.2 \mathrm{E}-04$ & $2.6 \mathrm{E}-04$ & $2.7 \mathrm{E}-04$ & - \\
Tomato J & - & - & $4.0 \mathrm{E}-04$ & $3.5 \mathrm{E}-04$ & $1.5 \mathrm{E}-02$ & $4.8 \mathrm{E}-04$ & $2.6 \mathrm{E}-04$ & $2.6 \mathrm{E}-04$ & - \\
RfDo & $4.0 \mathrm{E}-03$ & $2.0 \mathrm{E}-02$ & $4.0 \mathrm{E}-02$ & $4.3 \mathrm{E}-02$ & $7.0 \mathrm{E}-01$ & $15 \mathrm{E}-01$ & $1.0 \mathrm{E}-03$ & $1.4 \mathrm{E}-02$ & $3.0 \mathrm{E}-01$ \\
\hline
\end{tabular}

The daily intake at $(p<0.5)$ was highly significant, while at $(p>0.05)$ was not significant.

\section{Hazard index of heavy metals in canned tomatoes sold at Umuahia}

It was observed in Table 3 that the range of acceptable predictable lifetime-risk for carcinogens was below concentrations of canned tomatoes $(>1)$. Tomato $\mathrm{A}$ and $\mathrm{J}$ had the highest concentration while canned tomato $B$ and $G$ had the lowest concentration.

Table 3. Hazard index of heavy metals in canned tomatoes sold at Umuahia market

\begin{tabular}{lc}
\hline Canned tomatoes paste & Hazard index \\
\hline Tomato A & 0.3409 \\
Tomato B & 0.0648 \\
Tomato C & 0.8194 \\
Tomato D & 0.3000 \\
Tomato E & 0.0761 \\
Tomato F & 0.5853 \\
Tomato G & 0.0777 \\
Tomato H & 0.2915 \\
Tomato I & 0.3375 \\
Tomato J & 0.5792 \\
\hline
\end{tabular}

An $\mathrm{HI}<1$ indicates no adverse health effects, while $\mathrm{HI} \geq 1$ indicates the likelihood of adverse health effects. 


\section{Target hazard quotient (THQ) of heavy in canned tomatoes paste sold in Umuahia}

In Table 4, lead and nickel were not detected but copper, cobalt and iron were below the acceptable predicted ranges for non-cancer risk. Canned tomato $B, G$ and $H$ have the lowest concentration - $\mathrm{HQ}>1$, respectively. Canned tomatoes $\mathrm{I}$, and $\mathrm{C}$ had the highest concentration. Chromium, cadmium and manganese were below the acceptable predicted ranges for non-cancer risk - $\mathrm{HQ}<1$, but canned tomatoes $F, G$ and $E$ had the least concentration while canned tomatoes $A, F$ and $C$ had the highest concentrations. Canned tomato $\mathrm{C}$ had zinc concentration below the acceptable ranges for non-cancer risk. However, zinc was not detected in some other samples.

Table 4. Target hazard quotient (THQ) of heavy in canned tomatoes paste sold in Umuahia

\begin{tabular}{llllllllll}
\hline $\begin{array}{l}\text { Canned } \\
\text { tomatoes }\end{array}$ & $\mathrm{Pb}$ & $\mathrm{Ni}$ & $\mathrm{Cu}$ & $\mathrm{Co}$ & $\mathrm{Fe}$ & $\mathrm{Cr}$ & $\mathrm{Cd}$ & $\mathrm{Mn}$ & $\mathrm{Zn}$ \\
\hline Tomato A & - & - & 0.0143 & 0.0102 & 0.0275 & 0.0060 & 0.2600 & 0.0229 & - \\
Tomato B & - & - & 0.0113 & 0.0053 & 0.0038 & 0.0008 & 0.0250 & 0.0186 & - \\
Tomato C & - & - & 0.0093 & 0.0100 & 0.0529 & 0.0006 & 0.2400 & 0.0300 & 0.0005 \\
Tomato D & - & - & 0.0085 & 0.0060 & 0.0370 & 0.0006 & 0.2300 & 0.0179 & - \\
Tomato E & - & - & 0.0073 & 0.0084 & 0.0209 & 0.0009 & 0.0250 & 0.0136 & - \\
Tomato F & - & - & 0.0108 & 0.0056 & 0.0280 & 0.0001 & 0.2700 & 0.0192 & - \\
Tomato G & - & - & 0.0105 & 0.0047 & 0.0233 & 0.0006 & 0.0250 & 0.0136 & - \\
Tomato H & - & - & 0.0100 & 0.0040 & 0.0211 & 0.0007 & 0.2400 & 0.0157 & - \\
Tomato I & - & - & 0.0120 & 0.0119 & 0.0340 & 0.0004 & 0.2600 & 0.0192 & - \\
Tomato J & - & - & 0.0100 & 0.0081 & 0.0220 & 0.0003 & 0.2600 & 0.0185 & - \\
\hline
\end{tabular}

An $\mathrm{HQ}<1$ indicates no adverse health effects, while $\mathrm{HQ} \geq 1$ indicates adverse health effects.

\section{Carcinogenic metals in canned tomatoes sold at Ubani market}

Results in Table 5 revealed the absence of lead and nickel in cancer risk. The cancer risk detected for cadmium and chromium was within the cancer risk range predicted for life (1.0E-6 to 1.0E-4) for cancer. Canned tomato $A$ and $I$ had the highest cancer risk in cadmium while tomato $B$ and $H$ had the highest cancer range in chromium. Tomato $\mathrm{D}$ and $\mathrm{J}$ had the lowest cancer ranges. 
Table 5. Carcinogenic risk index of heavy metals in canned tomatoes pastes

\begin{tabular}{lcccc}
\hline Canned tomatoes & $\mathrm{Pb}$ & $\mathrm{Ni}$ & $\mathrm{Cd}$ & $\mathrm{Cr}$ \\
\hline Tomato A & - & - & $1.0 \mathrm{E}-04$ & $4.5 \mathrm{E}-04$ \\
Tomato B & - & - & $1.0 \mathrm{E}-05$ & $6.2 \mathrm{E}-04$ \\
Tomato C & - & - & $9.0 \mathrm{E}-05$ & $4.7 \mathrm{E}-04$ \\
Tomato D & - & - & $8.0 \mathrm{E}-05$ & $4.4 \mathrm{E}-04$ \\
Tomato E & - & - & $1.0 \mathrm{E}-04$ & $6.5 \mathrm{E}-04$ \\
Tomato F & - & - & $1.0 \mathrm{E}-04$ & $3.7 \mathrm{E}-04$ \\
Tomato G & - & - & $1.0 \mathrm{E}-05$ & $4.5 \mathrm{E}-04$ \\
Tomato H & - & - & $9.0 \mathrm{E}-05$ & $5.0 \mathrm{E}-04$ \\
Tomato I & - & - & $1.0 \mathrm{E}-04$ & $3.1 \mathrm{E}-04$ \\
Tomato J & - & - & $9.9 \mathrm{E}-05$ & $2.4 \mathrm{E}-04$ \\
\hline
\end{tabular}

\section{Total cancer risk of heavy metals in canned tomatoes}

The cancer total cancer risk was observed in all the samples of canned tomatoes. The total cancer-risk were within the predicted ranges for all the concentrations of canned tomatoes (1.0 E-6 to $1.0 \mathrm{E}-4)$, but canned tomato I and $\mathrm{G}$ had the least concentrations while canned tomato $\mathrm{B}$ and $\mathrm{D}$ had the highest concentrations of cancer risk.

Table 6. Total cancer risk of heavy metals in canned tomatoes

\begin{tabular}{cc}
\hline Canned tomatoes & Total cancer risk \\
\hline Tomato $\mathrm{A}$ & 0.00055 \\
Tomato B & 0.00063 \\
Tomato C & 0.00056 \\
Tomato D & 0.00052 \\
Tomato $\mathrm{E}$ & 0.00075 \\
Tomato $\mathrm{F}$ & 0.00047 \\
Tomato G & 0.00046 \\
Tomato H & 0.00014 \\
Tomato I & 0.00041 \\
Tomato J & 0.00040 \\
\hline
\end{tabular}

Carcinogenic risk $>1.0 \mathrm{E}-6$ indicates no hazard effect but $<1.0 \mathrm{E}-3$ indicate hazard health. 


\section{Discussion}

Any substance with the potential to causing harm, injury or death to human or animal is toxic. To determine whether the consumption of a finished food product can cause injury such as cancer, birth defects, immune deregulations and another associated adverse health effect to the populace is important. Exposure to a stressor (heavy metals) may generate different adverse health effects in a population. The protection of public health and the enhancement of nutrition and food quality is an issue for research and deliberation. The monitoring of heavy metals in canned tomatoes paste will help the various regulatory bodies and manufacturer of such products to ensure that elevated levels of heavy metals are not allowed in canned tomatoes paste, this is largely due to the toxicity of some of the metals. For instance, lead was found in some canned fish as a result of soldering of cans (Storelli et al. 2010). Lead can damage the kidney and may cause other diseases (Abou et al. 1996). Data in Table 1 revealed that lead and nickel were absent in all the canned tomatoes. Copper, iron, and manganese were detected in all the canned tomatoes paste at a lower concentration (Here, readers are referred to the Table without listing the values because the values are many and cannot be inserted here) compared to their respective permissible limits (Since elemental values are not listed, comparable values were not inserted). A higher concentration of chromium and cadmium (many values, See Table 1) were detected in all the canned tomatoes relative to their respective permissible limits. Canned tomatoes paste $\mathrm{E}$ and $\mathrm{J}$ have the highest chromium content, while the canned tomatoes paste $\mathrm{F}$ and $\mathrm{J}$ had $(0.055 \mathrm{ppm}$ and $0.003 \mathrm{ppm})$ of cadmium concentrations. Sample D had the lowest cadmium content together with Cobalt which was found in canned tomatoes paste $\mathrm{J}$. With the exception of canned tomato $\mathrm{C}$ whose zinc concentration was lower than it permissible limit, zinc was not detected in other canned tomatoes paste tested compared the concentration of several essential and toxic heavy metals in canned and corresponding fresh food from Saudi Arabia. He found that the toxic heavy metals were relatively high in concentrations in canned food than in their corresponding fresh food samples. They observed a variation in concentration in some of the heavy metals to exceed their permissible limits reported by different public health organizations. Similarly, (Hadiania et al. 2014) determined the content of several toxic heavy metals $(\mathrm{Pb}, \mathrm{Cd}$, and $\mathrm{As}$ ) in canned tomato paste and tomato sauces (ketchup) samples from Iran during the period 2010-2013 (Hadiania et al. 2014, Adnan et al. 2017). The authors found a lower concentration of heavy metals in all analyzed samples than the limits of national and international standards. They concluded that the consumption of canned tomatoes paste in Tehran was safe according to Iranian and Codex limits. Table 2 represents the daily intake of heavy metals in canned tomatoes paste. Obviously, they were no daily intake of lead and nickel from all the canned tomatoes analyzed. It was observed that they were daily intake of copper, cobalt, iron, chromium, manganese, and cadmium from all the canned tomatoes pastes, with all their daily intake values (DIV) below the tolerable daily level. The daily intake of zinc was in canned tomato $\mathrm{C}$ which was significantly below their permissible limit. Nickel and cobalt were below the permissible limit established for all the heavy metals (Szefer et al. 1993). Zinc is an essential trace element with low toxicity in humans (Wheal et al. 2016). Copper concentration was below the permissible limit. Cadmium toxicity may result in osteoporosis by inducing the dysfunction of renal tubular with consequent losses of calcium and phosphate as well as impairment of osteoblast and osteoclast activity (Berglund et al. 2000, Kazantziz 2004).

Table 3 shows the observed ranges of an acceptable predicted lifetime for the risk of carcinogens. Thus, their risk was low in all concentrations of canned tomatoes considerably $<1$. Tomato pastes $A$ and $J$ have the highest concentration, while canned tomatoes paste $B$ and $G$ had the lowest concentration. The non-cancer risk index (Target Hazard Quotient) of heavy metals in canned tomatoes paste is represented in Table 4, it shows the absence of lead and nickel in all the various canned tomatoes pastes. But copper, cobalt, and iron were below the acceptable predicted range for non-cancer risk indices. Although, canned tomatoes paste $\mathrm{G}$, $H$, and $B$ have the least concentration with Target Hazard Quotient less than $1(H Q<1)$, respectively. Canned tomatoes I, and $\mathrm{C}$ had the highest non-cancer risk. Chromium, cadmium, and manganese were below the 
acceptable predicted range for non-cancer risk with $\mathrm{HQ}<1$. The carcinogenic metals in canned tomatoes paste in Table 5 shows the absence of lead and nickel cancer risk in all the canned tomatoes sold at Ubani Market. The cancer risk detected for cadmium and chromium were within the cancer risk range predicted (1.0E-6 to $1.0 \mathrm{E}-4)$ for cancer. But canned tomato $\mathrm{A}$ and I have the highest cancer risk in cadmium, while canned tomatoes $B$ and $H$ had the highest cancer range of chromium, hence tomato $D$ and $\mathrm{J}$ has the least cancer range. Table 6 shows the total cancer risk observed in all the samples of canned tomatoes pastes, total cancer in all the samples were within the predicted range for all the concentrations of canned tomatoes $1.0 \mathrm{E}-6$ to $1.0 \mathrm{E}-4$, but canned tomato I and $\mathrm{G}$ has the least concentrations. This research was aimed at estimating the concentration of selected heavy metals $(\mathrm{Pb}, \mathrm{Zn}, \mathrm{Cr}, \mathrm{Ni}, \mathrm{Cu}, \mathrm{Co}$, and $\mathrm{Cd}$ ) in ten different brands of canned tomatoes paste sold in Ubani market Umuahia in Abia state Nigeria, to compare the results with those reported in other regulatory bodies in the world, and estimate the prevalence rates of canned food with exceeding permissible limits of these metals. Perceived health risk that may arise over time due to regular consumption of tomatoes paste was also calculate.

\section{Conclusion}

In this study, the levels of copper, cadmium, lead, nickel, chromium, manganese, iron, cobalt and zinc in canned tomatoes paste were investigated, the result shows that some heavy metals were present in selected canned tomatoes paste. Considerable differences were found among the various concentrations of canned tomatoes. The levels of cadmium and cobalt complied with the permissible limit. Chromium, manganese cadmium and zinc showed some degree of elevation. It is strongly suggested that heavy metal level in canned tomatoes paste should be monitor periodically to prevent heavy metals burden.

Conflict of Interest: the authors hereby declare no conflict of interest regarding the publication of this article.

Contribution: Authors contributed equally in the research and writing of this article.

\section{References}

Abou-Arab AAK, Ayesh AM, Amra HA and Naguib K (1996). Characteristics levels of some pesticides and heavy metals imported fish. Food Chemistry 57: 487-492.

Adnan M, Massadeh and Ayat A and Al-Massaedh T (2017). Determination of heavy metals in canned fruits and vegetables sold in the Jordan market. Environ Sci. Pollut. Res., https://doi.org/10.1007/s11356-017-0611-0.

Al-Thagafi ZA and Hassan RH (2014). Trace toxic metal levels in canned and fresh food: a comparative study. Int J Innov Res Sci Eng Technol, 3: 8977-8989.

Berglund M, Akesson A, Bjellerup P and Vahter M (2000). Metal-Bone interactions. Toxicological Lett., 113: 219-225.

Bradl $H$ (2002). Heavy metals interaction in the environment; origin, interactions, and remediation. London Academic Press (6): 11-39.

Chui S, Wong YH, Chio HI, Fong MY and Chiu YM (2013). Study of heavy metals poisoning infrequent users of Chinese medicines in Hong Kong and Macau. Phytother Research, 27: 859 - 863.

EPA (1989). Risk assessment guidance for Superfund, volume I. Human health evaluation manual, Part A. Office of Emergency and Remedial Response, U.S. EPA, Washington, DC.

EPA (1997). Exposure factors handbook. EPA/600/P-95/002Fc. Office of Research and Development, U.S. EPA, Washington, DC. http://www.epa.gov/ncea/exposfac.htm.

Farooq Y, Hussain MM, Aleem SB and Farooq MA (2008). Lead intoxication: the extent of the problem and its management. Pak Journal of Physiology, 4: 36-41. 
Guerra C, Nurchi VM, Fanni D, Gerosa C, Nemolato R and Faa G (2010). Copper-related diseases: from chemistry to molecular pathology. Coordination Chemistry Reviews, 254(7-8): 876-889.

Hadiania MR, Farhangib R, Soleimanic H, Rastegard H and Cheraghalib AM (2014). Evaluation of heavy metals contamination in Iranian foodstuffs: canned tomato paste and tomato sauce (ketchup). Food Addit Contam Part B, 7: 74-78.

He ZL, Yang XE and Stoffella PJ (2005). Trace elements in agroecosystems and impact on the environment. Journal Trace Elementary Medical Biology, 19 (2-3): 125-140.

Heidarieh M, Maragheh MG, Shamami MA, Behgar M and Ziaei F (2013) Evaluate heavy metal concentration in shrimp (Penaeus semisulcatus) and crab (Portunus pelagicus) with INAA method. Springerplus, 2: 72-75.

Kabata-Pandas A (2011). Trace elements in soil and plants. USA.

Kazantziz G (2004). Cadmium osteoporosis and calcium metabolis. Biometals, 17: 493-498.

Lasat MM (2006). Phytoextraction of metals from contaminated soil: a review of plant/soil/metal interaction and assessment of pertinent agronomic issues. Journal of Hazardous Substances Research, 2: 1-25.

Nathaniel B, John M, Sylvester T, Mercy B and Irene O (2012). Levels of selected heavy metals in canned tomato paste sold in Ghana, Food Additives and Contaminants: Part B (1-5). http://dx.doi.org/10.1080/19393210.2012.657250.

Nincevic GA, Grabaric Z, Pezzani A, Squitieri G, Fasanaro G and Imbimbo M (2009). Corrosion behavior of tinplate cans in contact with tomato puree and protective (inhibiting) substances. Food Addit Contam Part A, 26: 1488-1494.

Song Q and Li J (2014). The environmental effect of heavy metals derived from the e-waste recycling activities in China: A systematic review. Waste Management, 34(12): 2587-2594.

Stencheva M, Makedonski $L$ and Peycheva K (2014). Determination of heavy metal concentrations of most consumed fish species from Bulgarian black sea coast. Bulgarian Chemical Communications, 46(1): 195-203.

Storelli MM, Barone G, Cuttone G, Giungato D and Garofalo R (2010). The occurrence of toxic metals in fresh and canned tuna: public health implications. Food Chemistry Toxicology, 48(11): 3167-3170.

Szefer P, Penpkowiak J and Skwarzec B (1993). Concentrations of selected metals in penguins and other respective fauna of the Antartica. Science Total Environment, 138: 281-288.

Tchounwou PB, Yedjou CG, Patlolla AK and Sutton DJ (2012). Heavy metal toxicity and the environment. EXS Journal, 101: 133-164.

Wheal MS, Decourcy-Ireland E, Bogard JR, Thilsted SH and Stangoulis JCR (2016). Measurement of heam and total iron in fish, shrimp, and prawn using ICP-Ms: implications for dietary iron intake calculations. Food Chemistry, 201: 222229.

WHO/FAO/IAEA (1996). Trace elements in human nutrition and health. World Health Organization, Switzerland. Geneva 6(1): $22-25$.

Wu X, Cobbina SJ, Mao G, Xu H, Zhang Z and Yang L (2016). A review of toxicity and mechanisms of individuals and mixtures of heavy metals in the environment. Env. Science Pollution Research International, 23(9): 8244-8259.

Yang $L$ and Stofella $H$ (2005). Trace elements in agroecosystems and impact on the environment. Journal Trace Elementary Medical Biology, 19: 125-140. 